\title{
Methodology in the Interpretation of Roman Mithraic Imagery
}

\author{
Sean Brown
}

\begin{abstract}
The nature of a semiotic system is inherently complex. In the course of this paper, we will examine that nature through the application of linguistic anthropological theory. In so-doing, an interpretive methodology will be elucidated with particular attention given to the religious iconography of the Mithraic Mysteries found in imperial Rome. This multi-disciplinary approach to interpretation seeks to combine classical learning with the applied scientific approach of anthropology in the interest of providing a fresh perspective to an old question: "What does it mean?"
\end{abstract}

\section{Introduction}

The Cult of Mithras began in Rome in the first century of the Common Era after making a lengthy migration from the Persian lands of its origin, and continued to attract new acolytes until the fourth century when the practice of Mithraic worship fell into disuse in the newly Christianised Empire. The Cult of Mithras was a mystery cult and as such only those who had undergone initiation would have been made privy to the meanings behind rituals performed within the Mithraea, and to what imagery, such as the Tauroctony of Mithras, was truly communicating to the viewer. Being a mystery in the past has also contributed greatly to the mystery surrounding the goings-on of the Cult of Mithras for the modern scholar. With very little extant written documentation detailing, specifically, what happened in the pseudo-caverns of the Mithraea, interpretation of Mithraic belief and ritual is left mostly to the decipherment of the Mithraic imagery.

There are, however, certain clues which point the scholar in a helpful direction regarding their interpretations. The Persian origins of Mithraism have been examined by both modern scholars and the minds of the past, such as the philosopher Porphyry, and the details of Mithraism that are given homage in their writing have been valuable clues in the progression of the scholarship of Mithraism. A fairly large body of epigraphy has also been found detailing dedications to the god Mithras which, though only moderately helpful in the interpretation of the cult, has been certainly a valuable means of providing an insight into the type of person in the ancient world who would have had an interest in Mithraic worship. There is, however, still a certain amount of speculation involved in the decipherment of the cult when consulting these writings. The Persian Mithras and the Roman Mithras were not entirely synonymous with one another; the mythic story of the Persian Mithras does not appear to feature heavily, if at all, in the imagery which has been found in the Roman world, and the Roman Mithras is associated in some imagery with Roman figures such as Castor and Pollux. It should be mentioned here that the likelihood of the Castor and Pollux association being a Roman interpretation of imported, Persian, imagery through ascription is entirely possible.

There has been a great deal of publication on the subject of the Cult of Mithras. On the forefront of such is the recently published magnum opus from the Mithraic scholar Roger Beck on "The Religion of the Mithras Cult in the Roman Empire." 1 The new material provides a stunning study of

\footnotetext{
${ }^{1}$ Roger Beck, The Religion of the Mithras Cult in the Roman Empire (New York: Oxford Publishers), 2007.
} 
Mithraism. Beck provides us with the culmination of a lifetime of scholarship on the subject of Mithras while also building upon, knocking down, or elaborating upon ideas put forward previously by other scholars in the study of Mithraism. Beck's synthesis of decades of scholarly work on the Mithraic Mysteries has proven to be an invaluable resource in helping to direct the research for this paper.

The purpose of this paper is to examine the means by which images can be read, or misread, in an attempt to bring solidity to the interpretation of Mithraic imagery. In so doing, this paper will illuminate the pitfalls which stand between Mithraic scholarship and the truth for which it searches. Though we may never be absolutely certain as to the Mysteries of Mithras within the sphere of the Roman world, careful scholarship can, and has, brought us very close to an understanding of the Roman Mithraists, tentative though that understanding may be. Through continued scholarship, and the re-evaluation of previous work when held against new theories, this field of scholarship will show advances in our understanding of Roman Mithras. Given the highly social nature of religious practice and iconography, an approach will be taken herein which combines various fields of anthropological inquiry with evidence from archaeological excavation of Mithraic sites and classical scholarship of the Roman world which housed the Cult of Mithras. By taking a multi-field approach to the available evidence, this paper will attempt to provide insight into the interpretation of Mithraic imagery and cult practice in a Roman context.

\section{Images as Language - Sign and Signified}

A large problem which has created many pitfalls in the scholarship of the Roman Cult of Mithras over the course of the nineteenth and twentieth centuries has been the nearly two thousand year disconnect from the Roman Mithraists. Though such a historical distance seems immediately obvious, what is perhaps less obvious is that it creates an interpretive situation which is dangerously open to assumption, and the ascription of meaning to images due to the lack of hard evidence available regarding the mysteries. Archaeology can, and has, provided clues which have enriched our scholarly understanding of the Roman Mithraists. Among the upper echelon of these archaeological clues is the Mithraeum of Felicissimus, found at the site of Ostia in Italy, in which was discovered a beautiful floor mosaic depicting the seven grades of initiation within the Mithraic Mysteries. ${ }^{2}$

The archaeological clues can only give us part of the picture however. While they do provide us with the raw data needed to begin formulation of an interpretative hypothesis of the Mithraic Mysteries, they do not in themselves provide a key for the understanding of them. Imagery was often used in the classical world, and especially Rome, as a means of communicating ideas to viewers who were versed in the intricacies of the meanings depicted by the artist in his work. Such a means of communication through a strategic use of imagery and graphic signs is known in linguistic anthropology as a semantic system. An interpersonal semantic system relies on a mutual understanding between the originator and the viewer of what the meaning of each semantic sign depicted is. This is not to say that the 'creator' of the sign is privy to the meaning contained therein, such as the previously mentioned artist who may have simply been following instructions without understanding exactly what he was actually painting or sculpting. The ignorance of the sculptor is why I refer to the source of a sign as the 'originator', rather than the 'creator', so-as to avoid any possible confusion between the initiated Mithraist and the sculptor following a plan he did not understand.

${ }^{2}$ Robert Turcan, The Cults of the Roman Empire. Trans. Antonia Nevill (Malden: Blackwell Publishers, 1997), 224. 
A semantic sign is any type of graphically-depicted, often arbitrary (though not necessarily so), marking which contains an inherent and specific, though a posteriori, meaning. The problem with interpreting such signs is that by their sometimes arbitrary and often esoteric nature, they defy the viewer to recognise what communication is intended by the signs unless that viewer is knowledgeable as to their meaning prior to viewing them. Semantic signs work as mnemonic reminders of what the originator wished to communicate to their viewers without providing such detail that the uninitiated would be able to readily understand all levels of what is being communicated by any given semantic system. ${ }^{3}$ Mithraic imagery is just such a system, communicating ideas to the initiated viewer through an esoteric system of semantic signs which intentionally leave the uninitiated grasping for insight in order to decipher them. Such is the problem faced by the modern scholar when attempting to interpret the imagery of the Cult of Mithras in the Roman world without having the initiatory experience of the intended viewer of the imagery in question.

The lack of initiatory experience in the mind of the modern 'reader' of the semantic system being displayed in the Mithraic imagery creates a second pitfall faced by scholarship when attempting to formulate an interpretation of the images. Without being versed in the language' being spoken in the art through the use of esoteric image systems, the modern reader is prone to fallacy when formulating an interpretation of the meaning of the image in question. However, by recognising that the differences in the mindscape of an ancient Mithraist would have provided them with a different set of cognitive tools by which to decode the imagery, the modern scholar can avoid this particular pitfall. By recognising the differences in mindscape, one can distance themselves from their ancient counterparts and at once realise that the eyes through which they see the image before them are not the eyes of the ancient viewer looking at the same image, both literally and figuratively.

The distancing required by the mind of the modern scholar from the time in which it exists in order to facilitate a worldview compatible with that held by the ancient contemporaries of the Mithraic cult producing the imagery requires what is known as code-switching. In linguistic anthropology, code-switching is a term which describes the ability of an individual to switch between languages and their respective grammars in order to be better able to function in, and understand, a certain situation. ${ }^{4}$ The Sapir-Whorf hypothesis, put forward by anthropologists Edward Sapir and Benjamin Lee Whorf, posits that language is a major determinant of the worldview, and thereby the cognitive state, held by any and every individual. ${ }^{5}$ Therefore, this paper seeks to forward the notion that in order to be able to understand the semiotic images of Mithraic art, the modern scholar must first code-switch from his or her own contemporary worldview and state of cognition, into a state of cognition and worldview compatible with that of the ancient Mithraist. By so doing, the modern scholar opens up a new avenue of interpretation regarding the Mithraic imagery.

The necessary ability of an individual viewer in modernity to code-switch their mind between a worldview congruous to modern scholarship, to a worldview compatible with that of the ancient Mithraist also necessitates a thorough understanding of the world in which the Roman Cult of Mithras existed. The possession of a posteriori knowledge of the Roman world in which the Mithraic cult existed gives an immediate advantage to the scholarly classicist in their attempts to provide a valid interpretation for such things as the Tauroctony, and the Mithraeum as a whole, over the lay person viewing a fragment of Mithraic imagery in a museum, for example. Primarily, the modern reader of Mithraic imagery must understand that the worldview of Roman antiquity was based upon

\footnotetext{
${ }^{3}$ Harriet Joseph Ottenheimer, The Anthropology of Language (Belmont: Wadsworth Publishers, 2009), 184-185.

4 Ibid, 306-307.

5 Thomas Hylland Eriksen, Small Places, Large Issues (London: Pluto Press, 2001), 14.
} 
a mental state allowing for the inherent ability to separate variable meanings from the same semantic sign (i.e. image) into both a literal and a figurative meaning. ${ }^{6}$ Separating the literal viewing from the figurative viewing provides the means to understand that while we may see the literal viewing of the image of the Tauroctonous Mithras as an anthropomorphic representation of the god complete with a Phrygian cap, a cloak, and hands wielding a knife being plunged into the throat of a bull; such is not the only possible way that the image is to be viewed. Though certainly such a literal, violent viewing of the contents of the tauroctonous Mithraic imagery is the most immediately available to any person, initiated or otherwise, who casts their eyes upon the image, the figurative viewing of the Tauroctony provides the viewer with a different interpretation provided they are somewhat versed in the mythological excerpt being depicted by the bull-slaying. The reader with a basic understanding of Mithraic myth will also see, in the same tauroctonous image, the concept of the Sun (i.e. Mithras) rising undefeated above that which opposes him (i.e. the Moon), which is represented by the depiction of the Taurus constellation in the shape of a bull, ${ }^{7}$ to bring life and plenty to the world and its inhabitants. The concept of plenty is brought to the world through the actions of Mithras is illustrated by the ear of wheat sprouting from the tail of the slain bull. By slaying the bull, Mithras has brought life, and the fertility necessary to sustain life, to the Earth and is therefore worthy of heartfelt veneration by his followers. ${ }^{8}$

In formulating a scholarly interpretation for the imagery depicted in the Mithraic art, it is requisite that the interpreter have a thorough understanding of the Roman culture that provided a suitable social climate for the incubation of such a religion as Roman Mithraism. Through being well versed in said Roman culture, the interpreter would separate what is plausible in their interpretation from what is potentially preposterous. Before all else, he or she must have an understanding that what is being put forward is only an interpretation of the imagery in question, not an explanation for it, and is therefore provisional. Lastly, the interpreter must possess of a competent knowledge of astrology and astronomy in order not to overlook the astral symbolism to be found in the imagery, be it of either the aforementioned figurative or literal viewings. ${ }^{9}$

\section{Culture within the Mithraic Cult}

There are many pieces of evidence to be found in the archaeology of the Cult of Mithras which illuminate the culture of the Mithraists which was shared betwixt one another, which will be brought to light in this section. The Cult of Mithras was a mystery cult, that much we know already to be indisputable. Through being a mystery cult, the internal culture of the Mithraists would have functioned as a sub-culture within the larger framework of the Roman culture surrounding the mysteries. The presence of mysterious ritual being practiced in all of the Mithraea by the various grades of initiates further reinforces the sub-cultural nature of Mithraism.

Religious ritual functions as a form of social bonding between the practitioners of the rites involved, and serves to provide a tangible association for the initiated between the corporeal realm in which they exist, and the supernatural realm which is the subject of the ritual being performed. By performing such rituals behind closed doors for the eyes and ears of only the initiated, the Mithraists were legitimating their power; those things which were sacred to their god were unknown to the masses, and as such gave the power of receivership for divine providence from Mithras to them and them alone. Through the legitimation of their power in such a way, the ritual practices of Mithraism

\footnotetext{
${ }^{6}$ Beck, The Religion of the Mithras Cult, 190.

7 Porphyry. "On the Cave of the Nymphs," in De Antro. Trans. Thomas Taylor (Grand Rapids: Phanes Press, 1991$), 8$.

${ }^{8}$ W.J. Phythian-Adams, Mithraism (London: Constable \& Company Ltd., 1915), 49.

${ }_{9}$ Beck, The Religion of the Mithras Cult, 193-194.
} 
served as vehicles for the transference of Mithraic ideology to the initiated. The function of ritual practice on both the mind of the individual as well as the collective mind of the cult created a feeling of emotional community between the practitioners, thereby solidifying the Mithraic sub-culture as something separate from Roman culture-at-large. ${ }^{10}$

By definition, a sub-culture is a small group of people juxtaposed in relation to the larger population. Mithraism has been shown to be a religion of small groups by the very size of the Mithraea in which their cult practices were actualised; the Mithraeum of Casa di Diana at Ostia is a mere six meters wide by four meters long. ${ }^{11}$ Maintaining a small size for each of the cult centres would have reinforced the feeling of community amongst the practitioners of Mithraism by putting them each in close physical proximity to one another. Robert Turcan has suggested that this feeling of close community was perhaps reinforced by the daily practice of a communal meal within the Mithraeum, ${ }^{12}$ possible evidence for such meals being found through the presence of the remains of domestic animals within Mithraea. ${ }^{13}$

The high proliferation of Mithraea in population centres, such as Ostia, is further evidence for the desire of Mithraists to maintain small, close-knit communities of cultists. Keeping each centre small meant that when the population of practicing Mithraists grew, new centres of worship would need to be, and consequently were, formed. How this happens remains somewhat of a mystery; in order to create a new Mithraeum a certain amount of wealth would have been needed for the procurement of property in which to situate the new crypt, as well as to decorate it with the appropriate imagery such as the Tauroctony and zodiac. In addition to the wealth required for the physical creation of a new Mithraeum, it is also necessary that a fully initiated member of an existing Mithraeum be transplanted to the new site in order to direct the initiation of acolytes and ensure that Mithraic ritual was performed properly. There is no evidence of such a transplanting of senior members of the cult, but it seems to be beyond question that such a thing would have been absolutely necessary; one simply cannot assume that each Mithraeum was founded by someone who merely found the cult interesting (how could they, being uninitiated?) and wanted to start a new one for himself without having the slightest clue regarding what happened behind the closed doors of the mysteries. Therefore, hearkening back to the earlier mentioning of avoiding the preposterous when interpreting Mithraic practice and imagery, it must be so that a senior member of an existing Mithraeum left the cult centre in which he had been initiated in order to found a new one as the cult expanded. This paper will here put forward, albeit tentatively, that this 'colonising' of new Mithraea was the function of the Pater. The Pater (father) was the highest grade of Mithraic initiation. ${ }^{14}$ The Pater would have been the only grade capable of transferring the entire body of Mithraic ideology to the acolytes of a new Mithraeum as they underwent their own initiatory promotions.

The small nature of Mithraea was in keeping with the idea that such sites were to function as emulations of caverns. ${ }^{15}$ The cavern-like nature of the Mithraea created necessitated a positioning of Mithraea in out-of-the-way places, much like the caverns which they are set to emulate. There are no instances of Mithraea ever occurring along places of high traffic which would allow for a large spectatorship. At the site of Ostia, the many Mithraea present are all located in low-traffic areas such

\footnotetext{
${ }^{10}$ Eriksen, Small Places, Large Issues, 215-216.

11 Turcan, The Cults of the Roman Empire, 219.

12 Ibid.

13 Jaime Alvar, Romanising Oriental Gods. Trans. Richard Gordon (Leiden: Koninklijke Brill NV, 2008$), 352$.

${ }^{14}$ Franz Cumont, The Mysteries of Mithra, Trans. Thomas J. McCormack (Chicago: The Open Court Publishing Company, 1910), 152.

15 Porphyry. "On the Cave of the Nymphs," 2.
} 
as alley-ways, the posterior orientation of homes, or off the courtyards of horrea. In the instance of the aforementioned Mithraeum of Feliciisimus, there has been found a door leading to an adjacent street which had been walled up in the past in order to create a sense of privacy for those within. ${ }^{16}$

There have been postulations in the past of connexions between the Cult of Mithras with another Eastern cult: that of the great goddess Cybele. This connexion has been interpreted as a sort of dichotomous relationship between two cults of similar geographic origin that were sexually dimorphic in comparison. The Cult of Mithras was an androcentric cult which prohibited the initiation of women into the ranks of the devoted. In contrast, the Cult of Cybele was a cult of gynocentrism which was prohibitive of male acolytes. This relationship has been suggested to be one of conciliation between the initiates of Mithras, and those of the officially-sanctioned Cult of Cybele which provided support for the former. ${ }^{17}$ This theory has been recently reinforced with evidence from Ostia that the earliest Mithraea in the city had been built in close proximity to sites of worship for Cybele the Magna Mater (Great Mother), as well as through a shared imagery between the two cults related to the slaying of bulls. ${ }^{18}$ Through acknowledging aspects of cult practices which were shared between different organisations, we become more open to the possibility of identifying the imagery within a mystery cult such as that of Mithras with a greater degree of accuracy.

\section{Conclusions}

Throughout this paper there has been an attempt to elucidate some of the problems faced by the modern scholar in the interpretation of Mithraic imagery, and provide a route by which solutions to these dilemmas may be found. By first examining what constitutes the communicative properties of an image within the context of a semantic system, this paper has provided the reader with the knowledge that there is more to art, Mithraic art in this case, than often meets the eye. It has also been shown that through a careful understanding of what one is looking upon, combined with some background knowledge of the subject matter being depicted, a multi-levelled interpretation of the image in question can be rendered by the viewer into both the literal and figurative planes of meaning. In the process of finding a solution to the pitfalls of viewership regarding Mithraic art, this paper has also brought to light a need for the viewer to have sufficient contextual knowledge of the culture which fostered the proliferation of the Cult of Mithras in order to see the image through the eyes of the intended recipient.

The cultural knowledge required for a suitable interpretation of the Mithraic imagery has come largely from what little extant documentary evidence survived the ravages of time, as well as the archaeological evidence unearthed at the site of the Roman city of Ostia. This site was chosen due to the extensive remains of Mithraea in well-preserved condition which have been discovered there. The large body of reference provided by the Ostian excavations has contributed greatly to the understanding that Mithraea were small-scale cult centres that were replicated, rather than expanded, as the cultist population grew. This paper has also served to introduce two new theories into the field of interpretation of Mithraic imagery and cult practice. Firstly, that in order to begin the formulation of an interpretation for Mithraic art, it is requisite that the viewer code-switch their cognitive state from the worldview of their own 'modern-ness' to a worldview congruent with that of the ancient Mithraist in order to avoid improper ascription of ideas situated in modern contemporaneity onto ancient Mithraic imagery. Secondly, that the spread of Mithraea as the cult

\footnotetext{
${ }^{16}$ John Schreiber, "The Environment of Ostian Mithraism," in Garret Theological Studies 1: Mithraism in Ostia (Evanston: Northwestern University Press, 1967), 36.

${ }^{17}$ Cumont, The Mysteries of Mithra, 179.

18 John Schreiber, "The Environment of Ostian Mithraism," 38.
} 
population grew was facilitated by the relocation of the Pater from an existing Mithraeum to the site of a newly formed centre in order to facilitate the initiation of new acolytes into the Mithraic order. Hopefully, further research and new excavations will confirm, or contest, these theories.

The cult of Mithras was both mysterious and complex not just in modern scholarship, but to the ancient world in which it resided as well. This paper has sought to alleviate somewhat the complexity faced in modern scholarship by highlighting the interdisciplinary approach to interpretation through the application of theories from linguistic anthropology, cultural anthropology, and classical archaeology. By blending these cognitive fields with the hard evidence of classical archaeology, the appropriate methodology to be applied to the interpretation of Mithraic religious images has been elucidated. The multi-field approach to interpreting mysteries such as those of Mithras will provide the researcher with an appropriate milieu of tools to avoid the pitfalls which have been mentioned, and challenged, throughout this paper. 


\section{Bibliography}

Alvar, Jaime. Romanising Oriental Gods. Translated by Richard Gordon. Leiden, Brill NV, 2008.

Beck, Roger. The Religion of the Mithras Cult in the Roman Empire. New York: Oxford Publishers, 2007.

Cumont, Franz. The Mysteries of Mithra. Translated by Thomas J. McCormack. Chicago: The Open Court Publishing Company, 1910.

Eriksen, Thomas Hylland. Small Places, Large Issues. London: Pluto Press, 2001.

Ottenheimer, Harriet Joseph. The Anthropology of Language. Belmont: Wadsworth Publishing, 2009.

Phythian-Adams, W. J. Mithraism. London: Constable \& Company Ltd., 1915.

Porphyry. On the Cave of the Nymphs. Translated by Thomas Taylor. Grand Rapids: Phanes Press, 1991.

Schreiber, John. "The Environment of Ostian Mithraism." Garret Theological Studies Volume One: Mithraism in Ostia. Evanston: Northwestern University Press, 1967.

Turcan, Robert. The Cults of the Roman Empire. Translated by Antonia Nevill. Malden: Blackwell Publishers, 1997. 